verschiedene Sorten Indigo ergaben 9,41 bis 72,42 Proc. Indigotin.

Hiernach können die verschiedenen $\mathrm{Re}_{\mathrm{e}}$ sultate, welche bei Anwendung von verschiedenen Indigocarmin-Präparaten des Handels für den Sauerstoffgehalt des Wassers nach Schützenberger erhalten werden, nicht befremden; denn wenn keine zur Bindung des Sauerstoffs genügende Menge des aus dem Indigo blau gebildeten Indigoweiss vorhanden ist, so muss Sauerstoff entweichen.

Man könnte daran denken, die für ein gleiches Volumen Flüssigkeit vorhandene geringere Menge indigodisulfonsaures Natrium durch Zusatz eines grösseren Volumens Indigolösung zu ersetzen. Aber das ist nicht angängig, weil auf diese Weise schmutzige Färbungen entstehen, welche den Farbenübergang von Blau in Gelb bzw. Weissgelb nicht erkennen lassen.

Bèi Anwendung der $\mathrm{Sch}$ ütz en berg'schen Methode zur Bestimmung des in Wasser gelösten Sauerstoffs ist daher in erster Linie erforderlich, die gehaltreichste und reinste Sorte "Indigotin" ${ }^{\mathrm{zu}}$ verwenden und sich über die Beschaffenheit desselben vorher Rechenschaft zu geben.

\section{Über Indigobestimmung.}

Von

\section{Dr. Fritz Voeller.}

Die bislang gebräuchlichste Methode der Indigobestimmung ist diejenige nach Fr. Mohr mit Kaliumpermanganat, welche jedoch oftmals zu sehr ungenauen Resultaten führt, besonders bei Untersuchung geringer Indigomarken, in Folge von häufig vorkommenden organischen Beimischungen und der natürlichen Begleiter des reinen Indigoblaues, welche Stoffe mehr oder weniger reducirend auf Permanganat wirken und daher stets den Gehalt an reinem Indigoblau zu hoch erscheinen lassen, ganz abgesehen von der oftmals sehr undeutlichen Endreaction. Aut diese Mängel der Methode hin wird häufig absichtlich von Händlern durch Zusatz solcher Permanganat reducirender Stoffe viel gesündigt. Es kommt beispielsweise vor, dass Indigocarmin mit Oxalsäure verfälscht wird. An demselben Fehler, den Gehalt des Indigo an reinem Indigblau mehr oder weniger zu hoch finden zu lassen, kranken auch die übrigen bekannten Oxydationsmethoden, wie diejenige von Bolley mit Chlorwasser, Chlor- kalk oder chlorsaurem Kali und Salzsäure, ferner die Methode von Penny mit chromsaurem Kali und Schwefelsäure, sowie die von Ullgreen mit rothem Blutlaugensalz. Die Methode von Chevreul, welche auf Probefärben beruht, thut gute Dienste, kommt aber hier, weil keine analytische, sondern blosse Vergleichsprüfung, nicht in Betracht; dasselbe gilt von einer anderen auf colorimetrischem Vergleich beruhenden Indigowerthschätzung.

Die Reductionsmethoden von Pugh mit Eisenvitriol und Natronlauge, oder die von Fritzsche mit Traubenzucker, Alkalien und Alkohol, welche darauf beruhen, den Indigo in Indigoweiss überzuführen und dieses dann wieder zu Indigoblau zu oxydiren, zu trocknen und zu wägen, dürften auch leicht zu hohe Resultate ergeben, weil der gewöhnliche käufliche Indigo stets von verwandten Körpern begleitet ist, welche einen analogen Reductions- und Oxydationsprocess durchmachen und in Folge dessen stets als Indigoblau mitgefunden werden, wenn dieselben nicht vorher auf irgend eine Weise entfernt werden. Berzelius fand nämlich, dass ausser Indigoblau und Aschenbestandtheilen im unverfälschten Indigo hauptsächlich drei Bestandtheile vorkommen, welche er als Indigleim, Indigbraun und Indigroth unterschied. Von diesen lässt der Indigleim sich mit verdünnten Säuren ausziehen; er ist dem Pflanzenleim ähnlich und verhält sich wie Eiweisskörper, löst sich in Wasser und Alkohol und wird durch Gerbsäure gefällt. Das Indigbraun ist in Alkalien löslich und soll in denjenigen Indigosorten, bei deren Herstellung Kalk verwendet wird, in grösserer Menge vorhanden sein. Berzelius wäscht nun nach seiner Methode den zu untersuchenden Indigo mit Salzsäure oder Essigsäure aus, hernach mit Alkali und darauffolgendem Alkohol und heissem Wasser, er entfernt so Indigleim, Indigbraun und Indigroth und wägt den so bergestellten angeblich reinen Indigo. Nun enthält jedoch das so erzielte Indigoblau fast immer noch mehr oder weniger Kieselsäure, aus dem zur Herstellung des rohen Indigo verwendeten, meist stark mit Gangarth durchsetzten Kalk, oder es ist noch verunreinigt mit anderen erdigen Bestandtheilen, welche in Säuren und Alkalien unlöslich sind und also nach der Berzelius'schen Methode dem Indigogebalt zu Gute kommen.

Dieser Umstand veranlasste mich zu versuchen, ob nicht, an der Hand des Berzelius'schen Reinigungsverfabrens vorgehend, in dem so gewonnenen, schon ziemlich reinen Indigo, durch eine Stickstoffbestimmung nach 
Kjeldahl der wahre Gehalt an Indigoblau zu finden sei. Ich wählte zum Versuch einen mittleren Bengal-Indigo. Die Auswaschungen mit Säure, Natron, Alkohol und heissem Wasser sind mit Hülfe eines durchlochten Tiegels mit Asbestausfütterung unter Zuhülfenahme einer Saugpumpe schnell auszuführen. Man hat dann nur nöthig, den Asbestpausch mit dem Indigoblau zu trocknen und in einem etwa 250 cc fassenden Rundkölbchen mit 25 bis 30 cc concentrirter Schwefelsäure und einem Tröpfchen Quecksilber aufzuschliessen, das gebildete Ammoniak mit Natronlauge abzudestilliren und daraus durch Titration oder gewichtsaualytisch den Stickstoffgebalt zu bestimmen, den gefundenen Stickstoff in Procenten mit dem Factor für Indigoblau 9,36 zu multipliciren, um den Indigogehalt in Procenten zu erhalten.

Eine Stickstoffbestimmung in der eingesandten Probe ergab:

I. a) 8,28 Proc. $\mathrm{N}\}$ im Mittel 8,27 Proc. N.

Nach der Reinigung auf die oben beschriebene Wcise betrug der Stickstoffgehalt:

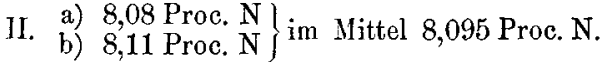

Letztere Zahl mit dem Factor 9,36 multiplicirt ergibt einen Indigogehalt von 75,76 Proc.

Die Differenz zwischen dem Gesammtstickstoff unter I und dem Indigostickstoff unter II, welche 0,175 Proc. Stickstoff im Mittel beträgt, würde auf die oben angeführten Indigobegleiter $z u$ vertheilen sein. Die Aschenbestimmung betrug 16,35, der Feuchtigkeitsgehalt 6,48 , also zusammengestellt:

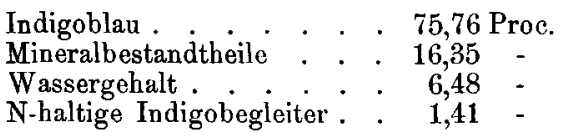

Wenn ich den Stickstoffgehalt von 0,175 , welcher sich aus der Differenz zwischen I und II ergibt, als zum grössesten Theil von Indigoleim herrührend betrachte und für denselben den Proteïnactor 6,25 anwende, so glaube ich, keinen grossen Fehler zu begehen; es würden darnach die stickstoffhaltigen Indigobegleiter auf 1,09 Proc. kommen.

Zur Controle der Methode habe ich mir aus einer grösseren Menge nach Berzelius gereinigten Materials sublimirtes Indigoblau hergestellt. Bei dessen Bestimmung, aus dem Stickstoffgehalt hergeleitet, fand ich im Mittel 99,85 Proc. Indigoblau.

Chemisches Untersuchungslaboratorium. Barmen, den 3. Februar 1891

\section{Bemerkungen über Phosphatlager in den Vereinigten Staaten.}

\author{
Von
}

\section{Dr. Otto Meyer.}

Die Phosphatindustrie Floridas, die eine sehr bedeutende $\mathrm{zu}$ werden verspricht, ist gegenwärtig erst im Werden begriffen, und zuverlässige Angaben über irgend welche Punkte scheinen ans verschiedenen Ursachen schwer zu erlangen zu sein. Aus diesem Grunde dürfte selbst das Wenige, das in Nachfolgendem enthalten ist, von Interesse sein. Diese Bemerkungen bilden die Erinnerungen an eine Reise, die sich auf nahezu ein Vierteljahr erstreckte und deren Zweck mit der Besichtigung und Untersuchung von Phosphatlagern in Florida und auch in Süd-Carolina im engsten Zusammenhange stand.

1. Süd-Carolinaer Phosphate. Dasjenige Phosphatwerk in der Nähe von Charleston in SüdCarolina, welches ich zu sehen Gelegenheit hatte und das typisch für die dortigen Anlagen zu sein scheint, gewann und verarbeitete die Phosphate in ziemlich einfacher Weise. Das Lager besteht dort aus Thon, in welchem die Phosphatknollen eingebettet sind. Der Abraum beträgt nur etwa $1 \mathrm{~m}$ und die Gewinnungsarbeit besteht darin, dass Arbeiter, meist Neger oder Italiener, mit Spaten, Schaufel und Pickaxt den Abraum hinwegschaffen und dann in gleicher Weise das Phosphat herausarbeiten, es in Schubkarren laden und nach dem nächsten Punkt des sich anschliessenden Bahngeleises karren. Hier schütten sie es in kleine, kastenartige Waggons, und wenn ein solcher Kasten gefüllt ist, so erhält der betreffende Arbeiter auf der Stelle seinen Zahlcheck; denn es herrseht das Accordsystem. Eine Locomotive sammelt dann die Kasten-Waggons und führt sie nach dem einige $\mathrm{km}$ entfernten Waschwerk. Hier wird der Thon durch einen einfachen Apparat von Stachelwalzen, verbunden mit einem langen Waschtrog entfernt; und auch das Trocknen geschieht in einfacher Weise durch Aufschichtung auf Holzscheite, die in Brand gesetzt werden.

In ganz anderer Weise geschieht die Gewinnung der sogenannten Flussphosphate in der Nähe der Hafenstadt Beaufort. Hier, z. B. in Coosaw River, bilden die Phosphatknollen stellenweise den Boden der Küstenflüsse und werden durch Bagger gehoben. Die Trockeneinrichtung einer Anlage, welche ich sah, bestand darin, dass von einem mit Holz gefeuerten Ofen ans ein System sich verzweigender Röhren ausging, durch welche die Feuergase in die übergeschichteten Phosphate drangen. Bei diesem Röhrensystem liefen die Seitenäste nicht nur wagerecht sondern waren auch schräg aufwärts einsetzbar.

Die Hauptgesellschaft in der Umgegend von Beaufort ist die Coosaw River Comp., welche 1876 von der Legislatur von Süd-Carolina das alleinige Recht, den Coosaw-Fluss bis zum März 1891 auszubeuten, bekam gegen eine Abgabe an den Staat von 1 Doll. für 1 t.

Diese Gesellschaft soll ausgezeichnete Geschäfte gemacht haben. In seiner letzten Botschaft an 